\title{
Motivations and barriers to death registration in Dakar, Senegal
}

\author{
Atoumane Fall ${ }^{1,2}$, Bruno Masquelier ${ }^{2^{*}} \mathbb{D}$, Khadim Niang ${ }^{3}$, Samba Ndiaye ${ }^{1}$ and Alphousseyni Ndonky ${ }^{4}$
}

\author{
${ }^{*}$ Correspondence: \\ bruno.masquelier@uclouvain.be \\ ${ }^{2}$ Centre de recherche en \\ démographie, UCLouvain, \\ Ottignies, Belgium \\ Full list of author information is \\ available at the end of the article
}

\begin{abstract}
Strengthening civil registration systems requires a better understanding of motivations and barriers related to the registration of deaths. We used data from the 2013 Senegalese census to identify deaths that are more likely to be registered in the Dakar region, where the completeness of death registration is higher than $80 \%$. We also interviewed relatives of the deceased whose death had been registered to collect data on reasons for registration and sources of information about the process. The likelihood of death registration was positively associated with age at death and household wealth. Death registration was also more likely in households whose head was older, had attended school, and had a birth certificate. At the borough commune level, the geographical accessibility of civil registration centres and population density were both positively associated with completeness of death registration. The main motivations for registering deaths were compliance with the legal obligation to do so and willingness to obtain a burial permit and a death certificate. Families, health facilities, and friends were the primary sources of information about death registration. Further research is needed to identify effective interventions to increase death registration completeness in Dakar, particularly amongst the poorest households and neighbourhoods on the outskirts of the city.
\end{abstract}

\section{Introduction}

A functional system of civil registration and vital statistics (CRVS) is widely recognized by the international community as a crucial component of development planning and good governance. Efficient CRVS systems help in establishing and managing the legal identity of individuals, generating electoral registers, and providing regular information on demographic trends for policy planning, including mortality and causes of death. Ultimately, CRVS systems can translate into better health of populations (Phillips et al., 2015). At the individual level, they guarantee access to key entitlements and services in the domains of health, education, and inheritance. Many targets adopted under the Sustainable Development Goals (SDGs) agenda, such as reducing neonatal and under-five mortality, require high-quality statistics from CRVS. One of the SDGs' targets (17.19) also tracks progress in birth and death registration for monitoring statistical capacitybuilding. However, in many low- and middle-income countries, progress has been limited and low completeness impairs the production of vital statistics. Globally, only $38 \%$ author(s) and the source, provide a link to the Creative Commons licence, and indicate if changes were made. The images or other third party material in this article are included in the article's Creative Commons licence, unless indicated otherwise in a credit line to the material. If material is not included in the article's Creative Commons licence and your intended use is not permitted by statutory regulation or exceeds the permitted use, you will need to obtain permission directly from the copyright holder. To view a copy of this licence, visit http:// creativecommons.org/licenses/by/4.0/. 
of deaths were registered in 2015, an increase from 36\% in 2010 (Mikkelsen et al., 2015). Death registration is particularly scarce in sub-Saharan Africa. Apart from South Africa and small island states, such as Mauritius and Seychelles, no country in the region has a comprehensive system of death registration with cause-of-death information (World Health Organization, 2018). Senegal, a middle-income country in West Africa, is no exception; according to the 2013 census, less than a third of deaths were registered at the national level (Agence Nationale de la Statistique et de la Démographie, 2014).

In recent years, there has been renewed interest in improving birth and death registration globally (Suthar et al., 2019; World Bank \& World Health Organization, 2014). Efforts have been devoted to assessing the status of CRVS systems (Mikkelsen et al, 2015), revising mechanisms for collecting causes of death (Savigny et al., 2017), modifying legal frameworks, and strengthening administrations in charge of civil registration. The Senegalese government is part of this effort. It has taken several initiatives to support its civil registration system. A National Directorate of Civil Registration (CNEC) was created in 2004. The modernization of civil registration system and exploitation of birth and death registration data are part of the National Development Plan (the "Plan Sénégal Emergent") and civil registration was elevated to a national priority by the President of the Republic of Senegal in 2015. The legislative framework is under revision, and the digitization of birth and death records is underway. Birth registration has improved in recent years; according to Demographic and Health Surveys, the percentage of children aged 0-4 whose birth was registered increased from 55\% in 2005 to $78 \%$ in 2019 . Death registration is lagging far behind as less than a third of all deaths are registered nationwide. There is also a sharp contrast between the completeness achieved in urban areas (61\%) and that in rural areas (12\%) (Agence Nationale de la Statistique et de la Démographie, 2014). More than $80 \%$ of deaths were registered in the Dakar region, which hosts the capital city of Senegal and accounts for half of the Senegalese urban population and more than a fifth of the total population of the country.

In this study, we focus on the Dakar region and aim to advance the understanding of motivations, or lack thereof, for obtaining a death certificate and the barriers to comprehensive death registration. First, to shed light on socioeconomic and cultural factors, we analyse data from the 2013 national census to characterize deaths that are most likely to be registered. We also use a study conducted in civil registration centres in the Dakar region among relatives of the deceased to identify reasons for death registration and sources of information. Second, to evaluate if the accessibility of registration offices can still play a role in this urban context, we combine census data and information on the locations and characteristics of registration offices to construct an index of geographical accessibility. Using a mixed-effects logistic regression model, we test whether accessibility of registration centres is associated with variations in completeness in death reporting after accounting for socioeconomic and cultural factors.

\section{Literature review}

There is extensive literature on the institutional factors that facilitate a well-functioning death registration system (the supply side) (Rao et al., 2004), but little attention has been devoted to relatives' knowledge of and interest in these services, their ability to access them, and their willingness to interact with the relevant authorities (the demand side) 
(Castle et al., 2020; UNICEF, 2005). The gap in the literature is particularly flagrant for death registration. Studies that explored barriers to birth registration point to lack of awareness of the importance of registration, financial barriers (including transportation costs and registration fees), difficulties in navigating the CRVS system, and inaccessibility or poor quality of services (Bennouna et al., 2016; Duff et al., 2016; Fagernäs \& Odame, 2013). To organize these different factors affecting birth registration, Bennouna and colleagues (2016) proposed using the model of the "three phases of delay", a framework initially developed by Thaddeus and Maine (1994) to examine barriers to access to obstetric care and identify interventions that could reduce maternal mortality. They organized factors into three categories: (a) socioeconomic and cultural factors (including motivation, the perceived value of the birth certificate, the perceived quality of service, and access to information), (b) accessibility (including distance, transportation options, and time off from work), and (c) quality of services (including the complexity of the procedure, waiting time, and competence of staff). These factors interact to introduce delays at three different stages. First, all three categories of factors can play a role in delaying the decision to apply for birth registration. Second, accessibility issues will delay identification of and contact with civil registration offices. Third, poor quality of service will further hamper registration and reception of the documents once relatives start interacting with legal authorities. Of course, when applying this theoretical framework to obstetrical conditions requiring care, delaying care can result in a fatal outcome or long-term complications. In the case of vital registration, the outcome is either late registration or failure to report the vital event.

This theoretical framework can be useful when identifying barriers to death registration as well, considering the similarities between the registration processes. In terms of socioeconomic and cultural factors, nationally representative surveys show that birth registration is more frequent when mothers have attended school, belong to the majority ethnic or religious group, and live in wealthier households (Bhatia et al., 2017; United Nations Children's Fund, 2013). We can expect death registration to be more frequent in wealthier and better-educated families as well, and registration to vary across religious and ethnic groups due to different cultural practices. Concerning accessibility, just as skilled attendance at birth increases the propensity to register births (UNICEF, 2005), a death occurring in a health facility is more likely to be registered, as some civil registration centres are associated with hospitals and health personnel can inform the relatives and caretakers on the procedures to follow. However, delaying factors may also differ from those that limit birth registration. In Guinea-Bissau, Fisker et al. (2019) compared the motivations for the registration of births and deaths of children, based on a study conducted among women of reproductive age. They observed that births went unregistered mostly due to paternal absence and administrative prerequisites, while the main reasons for the very low rate of death registration $(2 \%)$ were related to lack of knowledge of death registration and lack of perceived benefits. Lack of knowledge was also identified as the main obstacle to death registration in a rural area of Burkina Faso, where less than $7 \%$ of relatives of the deceased were aware of the need to register deaths (Niamba, 2020). In a recent study in rural Bangladesh, where less than $17 \%$ of deaths 
were registered, the two main reasons for not registering deaths were lack of awareness of the importance of registration (72\%) and not knowing what death registration is at all (32\% among men and 26\% among women) (Haider et al., 2021). Migration of household members after a death may also be a factor that reduces the propensity to register deaths, as was observed in Tanzania (Kabadi, 2013). Another difference with birth registration concerns variations by sex. Overall, few countries show significant differences in birth registration coverage by sex of the child (Bhatia et al., 2017). In the case of deaths, despite the scarcity of data, an underrepresentation of women in registered deaths has been observed in several countries (Haider et al., 2021; Center for Excellence for CRVS Systems, 2019). Finally, there are also fewer incentives to register a death. A birth certificate is often required for school enrolment or to gain access to health or welfare services. By contrast, in contexts, where funerals do not require a death certificate and inheritance, mechanisms do not systematically require the death to be registered, there are few incentives to register.

\section{Data and methods}

\section{Study area}

This study is focused on the Dakar region, which is subdivided into four departments (Dakar itself, Guediawaye, Rufisque, and Pikine) and 52 borough communes (Fig. 1).

The focus on the Dakar region is justified by the high level of completeness of death registration achieved, ranging from $76 \%$ in the department of Pikine to $88 \%$ in the department of Dakar. Barriers to recording deaths are likely to be quite different elsewhere in the country. The focus on the Dakar region is also motivated by previous studies in other African capitals, including Bamako (Fargues \& Nassour, 1988), Harare (Dlodlo et al., 2011), Abidjan (Garenne et al., 1995), Antananarivo (Masquelier et al., 2019). In these four capitals, vital registration data have helped in documenting mortality patterns. By comparison, the situation in Dakar has been little analysed. To our knowledge, there has only been one such study: it exploited vital registration data from the 1980s and highlighted the potential of such data to explore spatial heterogeneity in mortality rates (Salem, 1993). There has been no recent publication based on registered vital events, neither at the regional nor at the national level.

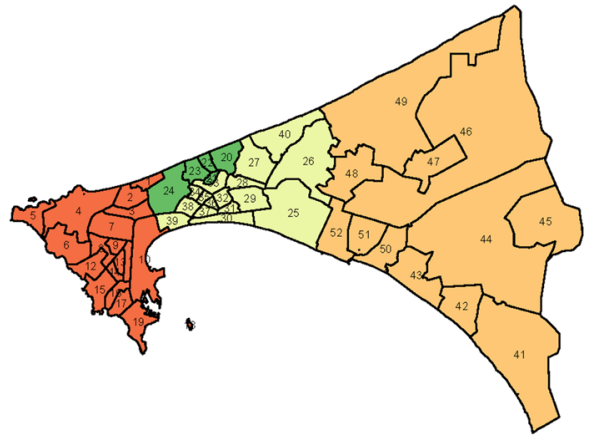

Fig. 1 Map of the Dakar region, its four departments and 52 borough communes

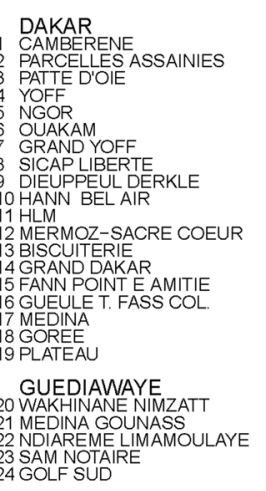

22 NDIAREME LIM

24 GOLF SUD

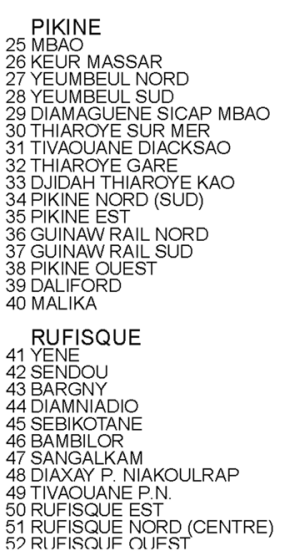

51 RUFSSQUE NORD (CENTRE)
5? RIJISOIJ OIJFST 
High completeness of death registration in the Dakar region is observed despite lower population coverage by civil registration centres. The region has one centre for more than 30,000 people, the lowest ratio in the country. However, civil registration centres in Dakar are more accessible and are better equipped; for example, more than $60 \%$ of centres in Dakar have a computer and $45 \%$ have a dedicated archive room, compared to only $27 \%$ and $18 \%$ nationally. Yet there are still equipment challenges, such as frequent stockouts of paper registers (Groupe d'Étude de Recherche et d'Appui au Développement, 2014).

The Senegalese CRVS system is highly decentralized, as the registration of vital events is placed under the responsibility of mayors. All deaths must legally be reported to the registrar within 1 month, and there are no fees for death registration. A previous study confirmed that this requirement was met in the Dakar region: $99 \%$ of deaths in the sample had been reported within 1 month and 62\% had been reported within 1 day of death (Salem, 1993). Later than one and a half months, late registration is possible but requires two witnesses or a death certificate from a doctor. Deaths may be reported by a family member or any person with the necessary information on his or her civil status. There are no penalties for late or absence of registration, and there is no real incentive to register the event either.

\section{Data}

This study uses three different data sources, as listed in Table 1 and detailed below.

\section{Census reports on recent household deaths}

The 2013 census included a module on household deaths that occurred in the 12 months before the data collection. For each of these deaths, a question was asked about whether it was reported to the civil registration system. This question had previously been included in census questionnaires in other countries (e.g., Namibia 2001, Nicaragua 2005, Belize 2010). It is not part of the United Nations' recommendations for census questionnaires (United Nations, 2017), presumably because it could be affected by reporting errors. In the Senegalese census, enumerators did not ask about the possession of death certificates and did not check if these certificates could be presented by the

Table 1 Data sources used for this study

\begin{tabular}{|c|c|c|c|}
\hline Data source & Year & Type of data & Information used \\
\hline National census & 2013 & $\begin{array}{l}\text { Individual-level data extracted } \\
\text { from the census database }\end{array}$ & $\begin{array}{l}\text { Age and sex of deceased } \\
\text { members who died in the } \\
12 \text { months before the census; } \\
\text { characteristics of their house- } \\
\text { hold }\end{array}$ \\
\hline $\begin{array}{l}\text { Administrative survey among } \\
\text { civil registration centres }\end{array}$ & 2017 & Aggregate data & $\begin{array}{l}\text { GPS coordinates of the civil } \\
\text { registration centres and their } \\
\text { characteristics }\end{array}$ \\
\hline $\begin{array}{l}\text { Survey among relatives of the } \\
\text { deceased }\end{array}$ & 2018-2019 & $\begin{array}{l}\text { Individual-level data from a } \\
\text { retrospective survey among } \\
\text { relatives of deceased persons } \\
\text { who died between December } \\
2018 \text { and February } 2019 \text { and } \\
\text { were reported to civil registra- } \\
\text { tion offices }\end{array}$ & $\begin{array}{l}\text { Reasons for registering deaths; } \\
\text { sources of information on } \\
\text { death registration }\end{array}$ \\
\hline
\end{tabular}


respondents. They only asked whether the death had been registered. The question may, therefore, lead to overestimating the true completeness of death registration if respondents refer to the notification of the death to a physician or the police instead of the CRVS system. This bias might or might not be counterbalanced by underreporting of deaths in the census itself. Demographic techniques (known as death distribution methods) have been developed to evaluate the completeness of death reporting in censuses, but they cannot be applied here as they require that net migration be negligible, which is not the case in the Dakar region (Moultrie et al., 2013). A simpler method, developed by Adair and Lopez (2018), estimates completeness based on expected relationships with crude mortality rate, child mortality, and the proportion of the population aged 65 years and older, informed by estimates from the Global Burden of Disease Study (Adair \& Lopez, 2018). However, we applied this method to census data from the Dakar Region and obtained an estimate of $67 \%$. This estimate suggests that census respondents omitted about a third of all deaths, which is implausible when considering the resulting mortality rates.

\section{Diagnostic surveys of the CRVS system}

In 2014, the National Statistical Office of Senegal conducted a diagnostic survey of the 689 civil registration centres in the country, collecting data on the number and qualifications of the staff, the status of premises, the equipment available, and the average annual number of civil status records recorded (Groupe d'Étude de Recherche et d'Appui au Développement, 2014). In 2017, this survey was updated and all centres were geocoded. We use the 2017 geocoded data to build an index of accessibility of the CRVS centres.

\section{Survey among relatives of the deceased about reasons for registering deaths}

In 2018-2019, we conducted a survey on all deceased persons reported to registration offices in the Dakar region between December 2018 and February 2019. The primary objective of the survey was to collect data on causes of death using a verbal autopsy. Verbal autopsies are interviews among relatives and caretakers of the deceased to collect data on circumstances and symptoms preceding the death through a structured questionnaire (Savigny et al., 2017). We augmented the standard WHO questionnaire (Byass et al., 2019) with questions related to motivations for registering deaths and sources of information, based on previous research in Guinea-Bissau (Fisker et al., 2019). A Likert scale was used to ask about the importance of registering deaths for various reasons (e.g., to obtain a burial permit or for inheritance) (see appendix, Section A1). Respondents were also asked about how they heard about death registration. We report here on results based on this subset of questions. In total, 3,075 deaths were reported in vital registration centres during the study period (December 2018-February 2019), and 98.0\% $(3,015)$ of these were registered in centres where we had trained staff for the study. Of these deaths, 65.4\% (1973) were eligible, because the deceased person was a resident of the Dakar region and had a relative residing in this region during the study period. For $86.5 \%(1,706)$ of the remaining deaths, relatives agreed to participate in the study at the registration centre, but in $21.8 \%$ of these cases, the informant for the verbal autopsy study eventually declined to be interviewed after the mourning period. In total, we were 
able to administer 1,315 complete interviews, which constitute our sample for this study (see the flowchart in Appendix, Section A2).

\section{Statistical analysis}

We first computed the completeness of death registration at the level of the 52 borough communes, based on the census reports. In $5.8 \%$ of cases, the respondents to the census did not know whether or not the death had been registered in the civil register. We assumed that these deaths were not recorded. Using Pearson's correlation coefficients, we tested for bivariate association between completeness and the crude death rate, the population density, and an index of accessibility of registration centres. This index was constructed based on the enhanced two-step floating catchment area (E2SFCA) method, originally developed to measure access to health care (Luo and Qi, 2009; Ndonky et al., 2015). The position of civil registration centres represented the supply side and the population density within a theoretical radius of attraction represented the demand side. Further details on the construction of this index are provided in Appendix, Section A2.

At the individual level, we measured the association between the age and sex of the deceased, the characteristics of his or her household, and death registration based on Chi-square tests. We used the sociodemographic characteristics of the head of household (age group, education, possession of a birth certificate), because we have no information on characteristics of the deceased (apart from sex and age at death). A composite measure of households' living standards was constructed based on multiple correspondence analysis (MCA). The variables included in the MCA came from the census and related to the occupancy status of the head of household, the materials used for housing construction (walls, roof, and floor), the types of sanitation facilities, access to drinking water, and whether some household members had skipped meals in the week preceding the census and/or given up health care in the preceding 12 months due to lack of resources. We extracted the first factor of the MCA and divided factor scores into quintiles.

We used fixed-effects logistic regression models to measure the association between the individual- and household-level characteristics and the likelihood of death registration. A mixed-effects regression model was also used to include random effects for borough communes and add contextual variables at this level (crude death rate, population density, and the accessibility index). Finally, from the study conducted among relatives of the deceased, reasons for registering deaths and sources of information were analysed with descriptive statistics. All analyses were performed in the R statistical software.

\section{Results}

\section{Descriptive statistics}

Figure 2 presents estimates of completeness of death registration, population density, crude mortality rate, proportion of households in the lowest quintile of living standards, proportion of adults aged $15+$ who have never attended school, and accessibility of registration centres at the level of the 52 borough communes in the Dakar region. It reveals 

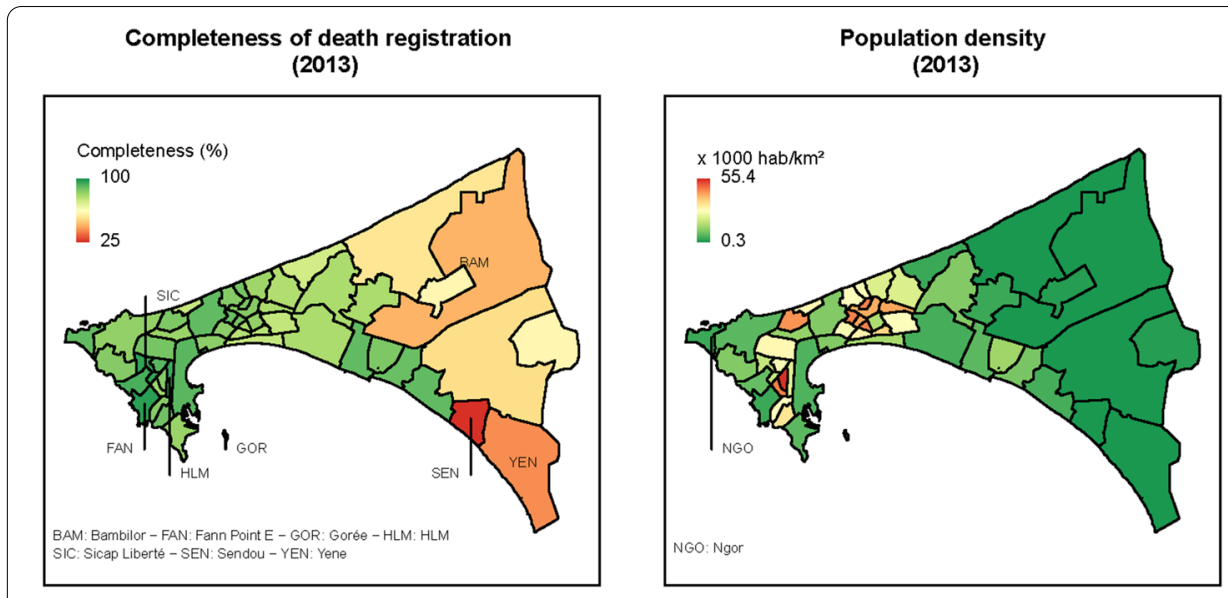

Sc: RGPHAE 2013

Crude death rate (2013)

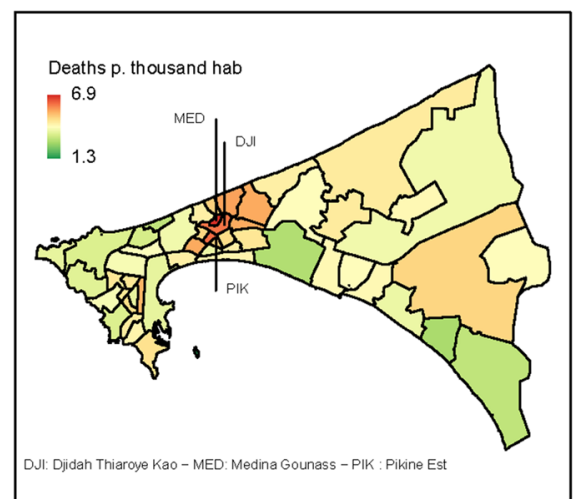

Sc: RGPHAE 2013

Proportion of adults who have never attended school (2013)

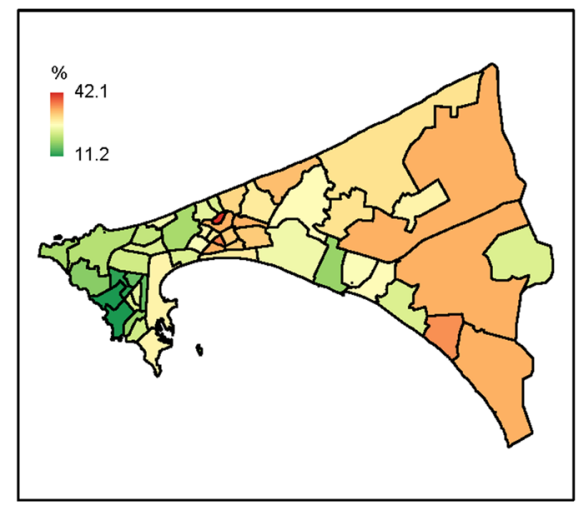

Sc: RGPHAE 2013

Sc: RGPHAE 2013

Proportion of $\mathrm{HH}$ in the poorest quintile (2013)

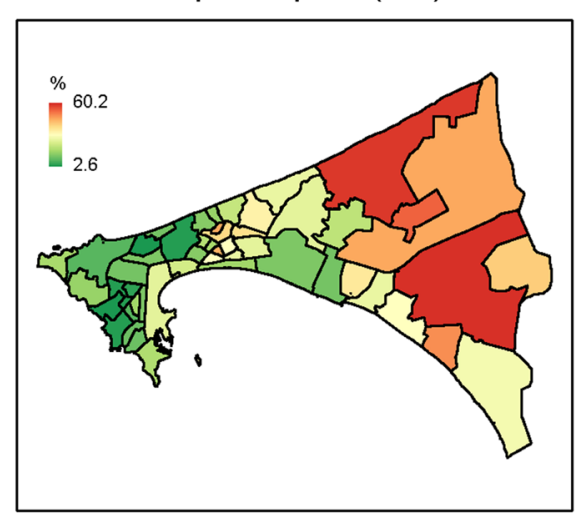

Sc: RGPHAE 2013

Accessibility of registration centers (2013-2017)

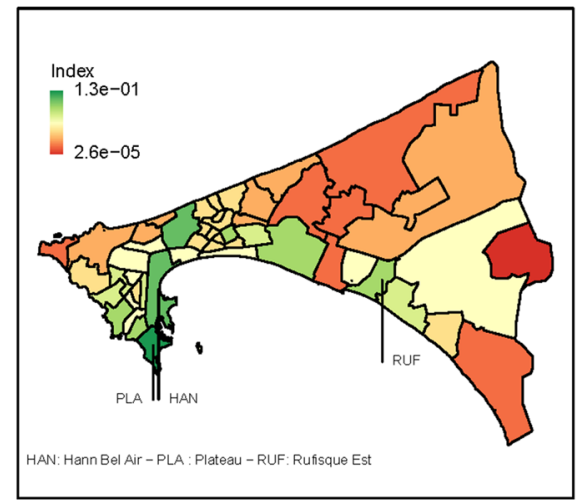

Sc: RGPHAE 2013/CRVS Survey 2017

Fig. 2 Completeness of death registration, population density, crude death rate, proportion of households in the lowest quintile, percentage of adults who have never attended school, and accessibility of civil registration centres, at the level of the 52 borough communes 
wide spatial heterogeneity in completeness, with levels ranging from less than $50 \%$ in the three communes of Sendou, Yene, and Bambylor (all located in the department of Rufisque) to more than $95 \%$ in the four communes of Gorée, Point E, HLM, and SicapLiberté (all located in the department of Dakar). The communes, where registration was the least frequent, located mainly in the east of the department of Rufisque, were also areas where the population density was relatively low $\left(<1000\right.$ inhabitants $\left./ \mathrm{km}^{2}\right)$, compared to the other communes of the region. However, completeness was high in other sparsely populated borough communes, such as Ngor in the western tip of the region. Variations in completeness did not follow the same spatial pattern as the crude mortality rate, whose spatial distribution was mainly characterized by a pocket of excess mortality in the three communes of Medina Gounass, Pikine Est, and Djidah Thiaroye Kao (CDR $>6$ per 1000). A gradient from the east to the west of the Dakar region is apparent in terms of household welfare, with less equipment in the department of Rufisque, as well as in a few communes located between Guediawaye and Pikine, where mortality is also higher. A similar gradient is observed with school attendance. Finally, our index of accessibility suggests that registration centres are much more accessible in the Dakar department, and especially in its southern tip (Plateau, Hann Bel Air), as well as in the communes bordering the bay, including the Rufisque Est, where Rufisque's main civil registration centre is located.

There is a positive and statistically significant association between the completeness rate of death registration and logged population density $(r=0.71)$, as well as with the log of the value of the accessibility index $(r=0.39)$ (Table 2$)$. The correlation is negative and significant with the proportion of households from the poorest quintile in the commune $(-0.63)$ and the proportion of adults who have never attended school $(-0.56)$. However, the crude mortality rate is not significantly correlated with the completeness of registration.

The descriptive characteristics of the census records are presented in Table 3, alongside the proportions of registered deaths by category. The likelihood of death registration was associated with all individual and household characteristics considered in this study ( $p<0.01$ for all variables except the sex of the deceased, for which $p=0.038$ ). There are substantial differences in death registration across age groups. Deaths of persons aged 60 years and over and of those aged 15-59 years were the most likely to be reported

Table 2 Correlation matrix of completeness of death registration, logged population density, crude death rate, logged index of accessibility of registration centres

\begin{tabular}{|c|c|c|c|c|c|}
\hline & $\begin{array}{l}\text { Completeness } \\
\text { of death } \\
\text { registry }\end{array}$ & $\begin{array}{l}\text { Logged pop } \\
\text { density }\end{array}$ & $\begin{array}{l}\text { Crude death } \\
\text { rate }\end{array}$ & $\begin{array}{l}\text { Proportion of } \\
\text { the poorest } \\
\text { quintile }\end{array}$ & $\begin{array}{l}\text { Proportion of } \\
\text { adults who } \\
\text { never attended } \\
\text { school }\end{array}$ \\
\hline $\begin{array}{l}\text { Logged pop. } \\
\text { density }\end{array}$ & $0.71^{* * *}$ & & & & \\
\hline Crude death rate & 0.15 & $0.39 * *$ & & & \\
\hline $\begin{array}{l}\text { Proportion of the } \\
\text { poorest quintile }\end{array}$ & $-0.63^{* * *}$ & $-0.49^{* * *}$ & 0.15 & & \\
\hline $\begin{array}{l}\text { Proportion of } \\
\text { adults who never } \\
\text { attended school }\end{array}$ & $-0.56^{* * *}$ & -0.13 & $0.35^{* *}$ & $0.73^{* * *}$ & \\
\hline $\begin{array}{l}\text { Logged accessibil- } \\
\text { ity index }\end{array}$ & $0.39^{* *}$ & 0.16 & -0.07 & $-0.28^{* *}$ & -0.22 \\
\hline
\end{tabular}


Table 3 Characteristics of deaths reported in the 2013 census in the Dakar region according to their registration $(n=12,973)$

\begin{tabular}{|c|c|c|c|c|c|c|c|}
\hline \multirow{2}{*}{ Sex of the deceased } & \multicolumn{2}{|c|}{$\begin{array}{l}\text { Death } \\
\text { registered }\end{array}$} & \multicolumn{2}{|c|}{$\begin{array}{l}\text { Death not } \\
\text { registered }\end{array}$} & \multicolumn{2}{|c|}{ Unknown } & $p$ value \\
\hline & & & & & & & \\
\hline Male & 6031 & $(83 \%)$ & 793 & $(11 \%)$ & 416 & $(6 \%)$ & 0.038 \\
\hline Female & 4786 & $(83 \%)$ & 670 & $(12 \%)$ & 277 & $(5 \%)$ & \\
\hline \multicolumn{8}{|l|}{ Age group of the deceased } \\
\hline $0-4$ & 1210 & $(71 \%)$ & 400 & $(23 \%)$ & 95 & $(6 \%)$ & $<2 \mathrm{e}-16$ \\
\hline $5-14$ & 492 & $(75 \%)$ & 126 & $(19 \%)$ & 41 & $(6 \%)$ & \\
\hline $15-59$ & 4396 & $(84 \%)$ & 511 & $(10 \%)$ & 308 & $(6 \%)$ & \\
\hline $60+$ & 4719 & $(87 \%)$ & 426 & $(8 \%)$ & 249 & $(5 \%)$ & \\
\hline \multicolumn{8}{|l|}{ Age group of the $\mathrm{HH}$ head } \\
\hline $10-29$ & 369 & $(76 \%)$ & 82 & $(17 \%)$ & 36 & $(7 \%)$ & $<2 \mathrm{e}-16$ \\
\hline $30-59$ & 6993 & $(82 \%)$ & 1,035 & $(12 \%)$ & 477 & $(6 \%)$ & \\
\hline $60+$ & 3455 & $(87 \%)$ & 346 & (9\%) & 180 & $(5 \%)$ & \\
\hline \multicolumn{8}{|l|}{ Education of the $\mathrm{HH}$ head } \\
\hline Never attended school & 3003 & $(78 \%)$ & 559 & $(15 \%)$ & 266 & $(7 \%)$ & $<2 \mathrm{e}-16$ \\
\hline Attended school & 7814 & $(85 \%)$ & 904 & $(10 \%)$ & 427 & $(5 \%)$ & \\
\hline \multicolumn{8}{|l|}{ Birth registration of $\mathrm{HH}$ head } \\
\hline Birth certificate & 8885 & $(85 \%)$ & 1,077 & $(10 \%)$ & 511 & $(5 \%)$ & $<2 \mathrm{e}-16$ \\
\hline Decree in lieu of birth certificate & 1519 & $(80 \%)$ & 282 & $(15 \%)$ & 109 & $(6 \%)$ & \\
\hline None & 157 & $(71 \%)$ & 48 & $(22 \%)$ & 17 & $(8 \%)$ & \\
\hline DK & 256 & $(70 \%)$ & 56 & $(15 \%)$ & 56 & $(15 \%)$ & \\
\hline \multicolumn{8}{|l|}{ Wealth quintiles } \\
\hline Richest & 1608 & $(90 \%)$ & 110 & $(6 \%)$ & 71 & $(4 \%)$ & $<2 \mathrm{e}-16$ \\
\hline Richer & 1713 & $(88 \%)$ & 159 & $(8 \%)$ & 77 & $(4 \%)$ & \\
\hline Middle & 2133 & (86\%) & 232 & (9\%) & 122 & $(5 \%)$ & \\
\hline Poorer & 2542 & (82\%) & 402 & $(13 \%)$ & 163 & $(5 \%)$ & \\
\hline Poorest & 2752 & (77\%) & 554 & $(16 \%)$ & 257 & (7\%) & \\
\hline \multicolumn{8}{|l|}{ Department } \\
\hline Dakar & 3728 & (88\%) & 322 & (8\%) & 178 & $(4 \%)$ & $<2 \mathrm{e}-16$ \\
\hline Guediawaye & 1332 & (87\%) & 131 & (9\%) & 70 & $(5 \%)$ & \\
\hline Pikine & 4305 & (81\%) & 658 & $(12 \%)$ & 326 & $(6 \%)$ & \\
\hline Rufisque & 1452 & (76\%) & 352 & $(18 \%)$ & 119 & $(6 \%)$ & \\
\hline
\end{tabular}

(respectively, $87 \%$ and $84 \%$ ), while only $71 \%$ of deaths of children under 5 years of age and $75 \%$ of children aged 5-14 years were registered. Deaths occurring in households with a head who is older or has been to school or has a birth certificate (or a supplementary judgment) are also more likely to be registered. Living in the poorest quintile significantly decreased the likelihood of death registration: $90 \%$ of deaths in the richest quantile were registered, against $77 \%$ in the poorest quintile. As observed in Fig. 2, this partly reflects differences between departments, as households are on average richer in the Dakar department, where registration is more systematic.

To explore these associations in a multivariate analysis, we coded cases where the respondent was unsure about registration by considering that the death had not been registered. Table 4 presents the odds ratios obtained from a fixed-effects logistic 
Table 4 Odds ratios from the fixed-effects and mixed-effects models

\begin{tabular}{|c|c|c|c|c|}
\hline & & \multicolumn{2}{|c|}{ Fixed-effects model } & \multirow{2}{*}{$\begin{array}{l}\text { Mixed-effects mode } \\
\text { (3) }\end{array}$} \\
\hline & & (1) & (2) & \\
\hline \multicolumn{5}{|l|}{ Individual characteristics } \\
\hline Sex of the deceased & Female & 0.995 & 0.968 & 0.962 \\
\hline Age of the deceased & $0-4$ & $0.455^{* * *}$ & $0.503^{* * * *}$ & $0.506^{* * * *}$ \\
\hline \multirow[t]{2}{*}{ (ref: 15-59) } & $5-14$ & $0.549^{* * * *}$ & $0.602^{* * *}$ & $0.627^{* * * *}$ \\
\hline & $60+$ & $1.302^{* * * *}$ & $1.275^{* * *}$ & $1.277^{* * * *}$ \\
\hline \multicolumn{5}{|l|}{ Household characteristics } \\
\hline Education of the $\mathrm{HH}$ head & Attended school & & $1.540^{* * * *}$ & $1.536^{* * *}$ \\
\hline Age of the $\mathrm{HH}$ head & $10-29$ & & $0.728^{* * * *}$ & $0.680^{* * * *}$ \\
\hline (ref: 30-59) & $60+$ & & $1.454^{* * *}$ & $1.382^{* * * *}$ \\
\hline Wealth quintiles & Poorer & & $1.170^{* *}$ & $1.136^{* * * *}$ \\
\hline \multirow[t]{3}{*}{ (ref: Poorest) } & Middle & & $1.396^{* * *}$ & $1.302^{*}$ \\
\hline & Richer & & $1.618^{* * * *}$ & $1.583^{* * * *}$ \\
\hline & Richest & & $1.638^{* * * *}$ & $1.515^{* * * *}$ \\
\hline Birth certificate & Birth certificate & & $1.821^{* * * *}$ & $1.747^{* * * *}$ \\
\hline \multirow[t]{2}{*}{ (ref: None) } & $\begin{array}{l}\text { Decree in lieu of } \\
\text { birth certificate }\end{array}$ & & $1.413^{* *}$ & $1.453^{*}$ \\
\hline & DK & & 0.790 & 0.796 \\
\hline \multicolumn{5}{|l|}{ Contextual characterictics } \\
\hline Department & Guediawaye & & 1.005 & \\
\hline \multirow[t]{2}{*}{ (ref:Dakar) } & Pikine & & $0.766^{* * *}$ & \\
\hline & Rufisque & & $0.508^{* * * *}$ & \\
\hline Index of accessibility (logged) & & & & $1.133^{* * * *}$ \\
\hline Population density (logged) & & & & 1.021 \\
\hline Crude death rate & & & & $1.338^{* * * *}$ \\
\hline Constant & Constant & $5.379^{* * * *}$ & $2.211^{* * * *}$ & $0.274^{*}$ \\
\hline Observations & & 12,973 & 12,895 & 12,895 \\
\hline Log likelihood & & $-5,701.115$ & $-5,463.310$ & $-5,327.8$ \\
\hline Akaike inf. crit & & $11,412.230$ & $10,962.620$ & $10,693.7$ \\
\hline
\end{tabular}

${ }^{*} p<0.1 ;{ }^{* *} p<0.05 ;{ }^{* * *} p<0.01$

regression model including only the age and sex of the deceased (model 1). Model 2 includes the characteristics of the households (age and education of the head of household, wealth quintiles, possession of a birth certificate) and the department. The last column of Table 4 displays the odds ratios from a mixed-effects model including a random effect for borough communes and incorporating the contextual variables.

Results from the fixed-effects models suggest that there is no significant variation by sex of the deceased once age is controlled for. Adults aged 15 to 59 and people over 60 are the most likely to have their death registered. Odds ratios related to characteristics of the head of household are also in line with our descriptive results. Deaths in the richest households are 1.6 times more likely (95\% CI: 1.4-2.0) to be registered than those in the poorest quintile. Deaths occurring in households whose head has a birth certificate or has attended school are, respectively, 1.8 times (95\% CI: 1.3-2.5) and 1.5 times (95\% CI: 1.4-1.7) more likely to be registered. In the fixed-effects model, the departments of Dakar and Guediawaye do not differ in terms of completeness of death registration, after controlling for individual and household characteristics (OR 1.0, 95\% CI: 0.8-1.2). 


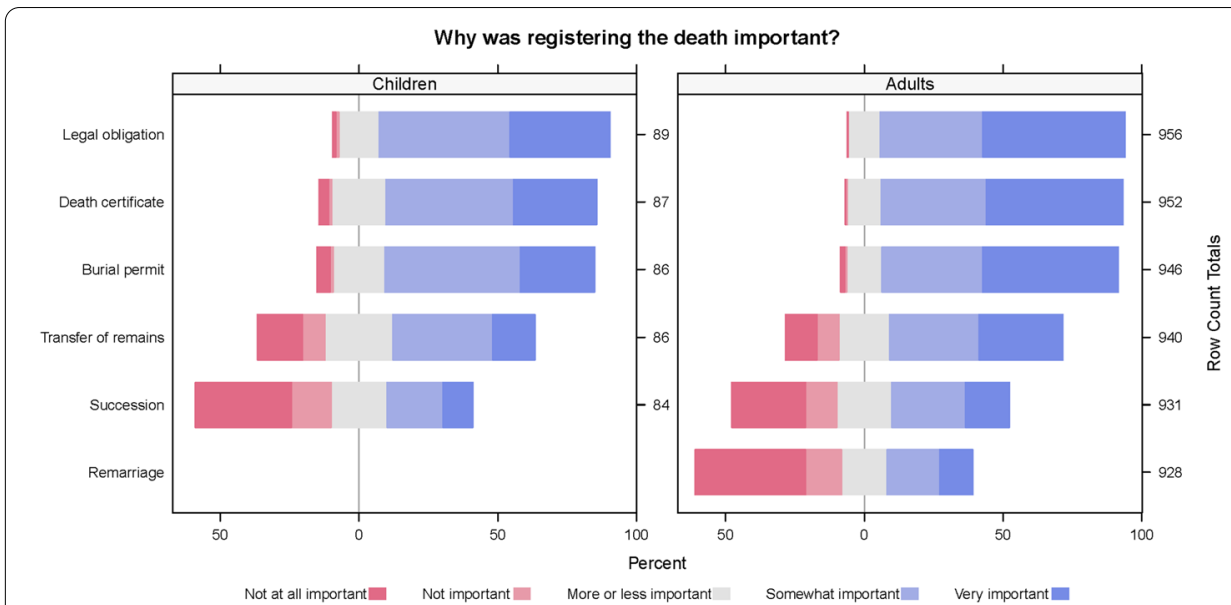

Fig. 3 Motivations for registering deaths of children and adults

Deaths of residents in Pikine and Rufisque are, respectively, 0.8 (95\% CI: 0.7-0.9) and 0.5 (95\% CI: 0.4-0.6) times less likely to be registered than in Dakar.

The odds ratios in the mixed-effects logistic regression model are very similar to those obtained from the fixed-effects models for individual and household variables. This last model also suggests that the likelihood of death registration is positively associated with the logged value of our index of accessibility of death registration centres (OR 1.1, 95\% CI: 1.1-1.2), and positively associated with logged population density (OR 1.3, 95\% CI: 1.2-1.5). However, it is not significantly associated with the crude death rate of the commune, confirming the observations based on the bivariate correlation coefficients.

\section{Reasons for registering deaths and sources of information}

In this section, we report on reasons for registering deaths, based on data collected with relatives of the deceased reported to civil registration centres from December 2018 to February 2019. These relatives were mainly the parents of the deceased (39\%), children (19\%), spouse (9\%), or other family members (30\%). Of these, $90 \%$ lived with the deceased before his or her death. The survey sample consisted of $45 \%$ female deaths, $20 \%$ newborns or stillbirths, $6 \%$ children between 28 days and 14 years, 39\% individuals between 15 and 64 years and 35\% individuals over 65 years. It is worth noting that stillbirths were supposed to be excluded from the sample. They are normally recorded in dedicated registers, or identifiable through a note in the death register (as provided for in the Family Code). Some stillbirths declared as live births in civil registration centres were, however, identified in the sample at the time of analysis, through questions in the verbal autopsy questionnaire (e.g., "did the baby cry at least once?", etc.). Based on these questions, 127 stillbirths could be identified, representing 9.7\% of the total number of deaths subject to verbal autopsy. These results suggest that a significant proportion of deaths reported to the civil registry should not be included in the classic mortality indicators, but should be subject to specific treatments reserved for measuring stillbirths. 


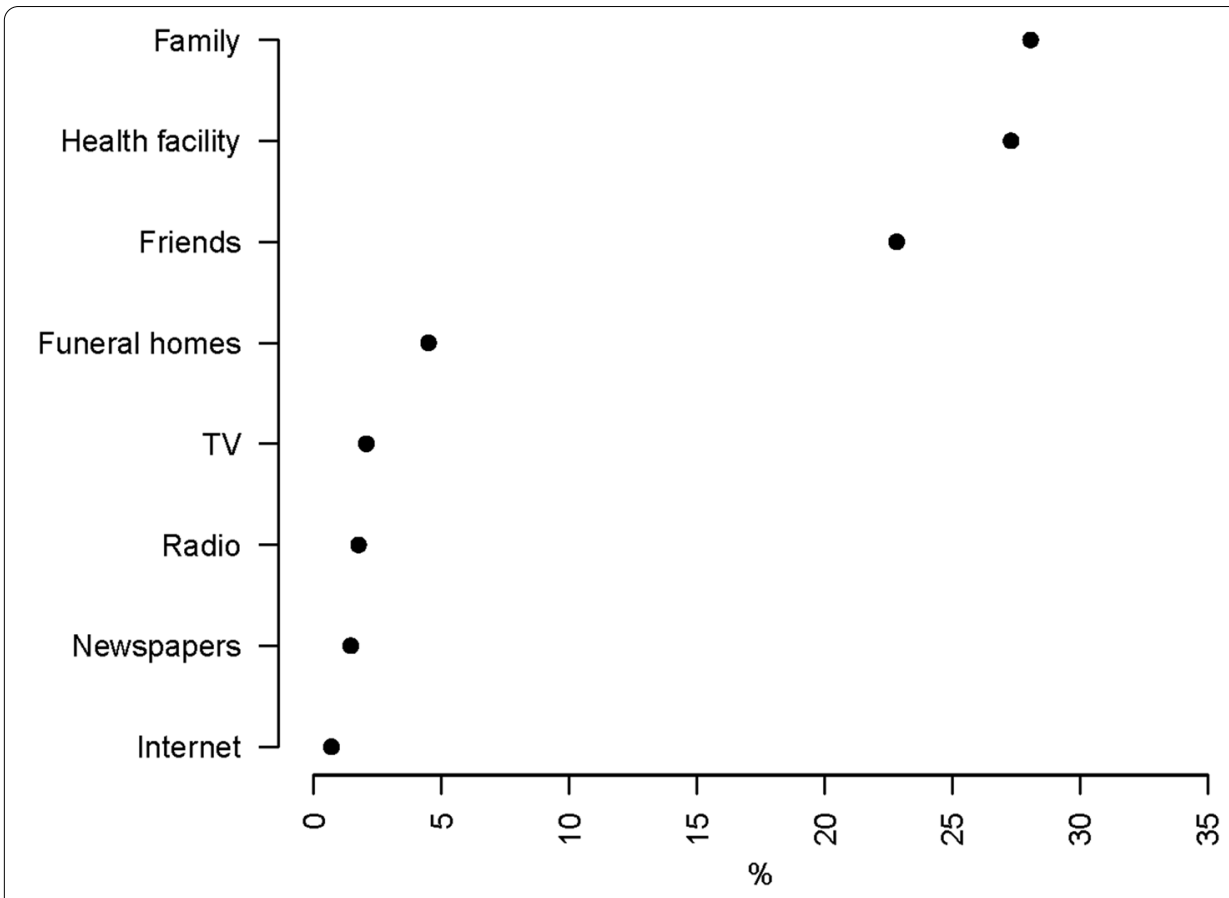

Fig. 4 Sources of information about death registration

In $60 \%$ of the cases, the person about to die travelled to a health facility or a hospital in the final days before death. Home death represented $47 \%$ of our sample; $47 \%$ of deaths occurred in a health facility, and $6 \%$ on the way to a health facility. In $73 \%$ of the cases, the respondent had received the death registration certificate.

As shown in Fig. 3, the three items considered most important when registering deaths were compliance with the legal obligation, obtaining a death certificate, and obtaining a burial permit. In comparison, the permission to transfer remains was considered less important, as were inheritance issues (especially for child deaths) and possible remarriage procedures.

When asked about sources of information on death registration, relatives of the deceased identified family, health facilities, and friends as the three main sources. In comparison, funeral homes were rarely mentioned, and sources such as television, radio, newspapers, and the internet were reported as sources of information in less than $5 \%$ of cases (Fig. 4).

\section{Discussion}

There is a prolific production of statistics in Senegal for the study of demographic dynamics and the evaluating of development programs, thanks to regular censuses and sample surveys complemented by three Health and Demographic Surveillance Systems in rural areas (Pison et al., 2018 Delaunay et al., 2013; Pison et al., 2014). However, the CRVS system, needed to obtain timely information on mortality and causes of death at a small geographical scale, remains deficient. While about a third of all deaths are 
registered nationally, the Dakar region stands out as having much higher completeness, potentially paving the way for continuous monitoring of mortality in this region. Our study highlights the categories of deaths that still go unregistered and suggests ways to improve completeness. The census and survey data do not allow us to distinguish the three phases of delay from Thaddeus and Maine's model (Bennouna et al., 2016; Thaddeus \& Maine, 1994) (deciding to notify the death, identifying and reaching the registry office, submitting the documents and registering the death). Nevertheless, they shed light on two categories of factors that affect registration: (1) socioeconomic and cultural factors, and (2) accessibility of the service.

On the first set of factors, our study highlighted that the poorest households and those whose heads of households have not been educated are less likely to have their deaths registered. This information should be taken into account when preparing awareness campaigns. Even when the procedure is free, there is an opportunity cost associated with the time that must be spent and the time away from work. The positive link between the possession of a birth certificate by the head of household and the death registration of household members should also inform interventions aimed at strengthening CRVS. Efforts to promote the registration of vital events through information, education, and advocacy should not consider births and deaths separately. Another important result from this study is the lack of association between death registration and the gender of the deceased. By contrast, there were ample variations by age. Deaths of adults aged 60 and over were significantly more likely to be registered than those of adults aged 15 to 60. This result has important implications for mortality measurement from death registration data. Demographic techniques aimed at adjusting vital registration generally assume that the completeness of death registration is invariant by age (above a certain age in adulthood) (Moultrie et al., 2013). This assumption is unlikely to be met in practice, introducing biases in completeness estimates. Besides, because deaths in children are significantly less likely to be registered, under-five mortality will be underestimated if deaths in young children are adjusted upwards based on completeness levels estimated in adults.

Turning to motivations for registering deaths, our study suggests that the exercise of inheritance and remarriage rights, often cited as the main incentives of registration, are not necessarily the primary motivations. According to relatives of the deceased, compliance with the legal obligation was more important, as well as obtaining the necessary documents immediately after the death. The importance given to the burial permit calls for systematic monitoring of cemeteries to make burial conditional on the registration of deaths. Information sources about death registration were mostly informal (family and friends), and awareness-raising campaigns should take this into account to mobilize existing family and social networks and perhaps local leaders (rather than be organized through traditional media campaigns). The role played by health facilities was important (the second most frequent source), but efforts to promote registration should not focus solely on health facilities, because a significant proportion of deaths occur at home (47\%), even in an urban setting such as Dakar. 
On the accessibility of services, we showed that the likelihood of registration was associated with accessibility of civil registration centres and population density, which suggests that real or perceived lack of access to registration offices still plays an additional role in hampering the reporting of deaths, even after controlling for standards of living. The least populated and most isolated communes on the outskirts of Dakar, especially in the eastern zone of Rufisque, should be considered as a priority when setting up new centres to increase the propensity to register deaths.

Our study has some limitations and could be extended in several ways. First, census data could be biased by the omission of some deaths or by recall errors about the registration of deaths. Second, we only explored here the motivations for registration among registered deaths, but it would be necessary to investigate unregistered deaths. A study of this type was carried out in a Health and Demographic Surveillance System (HDSS) in Guinea-Bissau (Fisker et al., 2019) and should be conducted in other HDSS, including those located in Senegal. Third, we focused our attention here on the Dakar region, but further research is needed on barriers to registration elsewhere in Senegal, particularly in rural areas, where travel costs are probably much higher. Burials that occur in rural areas do not require a burial permit, which will also reduce incentives for registration. Our census-based study identified poverty level, lower education level, and lack of accessibility of registration centers as key determinants of under-registration, but proactive searches for unregistered deaths, such as through cemetery surveillance, and cross-checking death registers with hospital or funeral home registers, would help to more accurately profile unregistered deaths (Szwarcwald et al., 2014). Qualitative studies would also help in improving our understanding of motivations for and barriers to death registration. Additional studies are needed to define the best interventions to increase registration, especially in the poorest neighborhoods on the outskirts of the city. This study could also be complemented by an analysis of data from civil registration centres, including the distribution by sex and age of reported deaths as well as spatial variations in the completeness of registration. However, this would first require the development of a centralized database compiling all vital events registered in the country, a first step towards the production of vital statistics from the CRVS system in Senegal.

\section{Appendix}

\section{A. 1. Questions asked about death registration}

A- How important were the following elements in the decision to register the death at the civil registration office? (a) the legal obligation, (b) obtaining a death certificate, (c) obtaining authorization for the transfer or repatriation of mortal remains, (d) remarriage procedures, (e) procedures related to inheritance.

For all these questions, the respondents could select a score ranging from 0 to 5: 0 (not at all important), 1 (not important), 2 (more or less important), 3 (somewhat important), 4 (important), 5 (very important).

$B$ - How did you hear about the importance of registering a death with the civil registry? (several answers possible): (1) medical personnel, (2) funeral home, (3) radio, (4) television, (5) print media, (6) internet, (7) friends/relatives, (8) family. 


\section{A.2. Flowchart of the selection of respondents for the survey among relatives}

\begin{tabular}{|c|c|c|}
\hline Identification of the deceased & $\begin{array}{l}\text { Death } \\
\text { the }\end{array}$ & $\begin{array}{l}\text { tified from } \\
\text { enters }\end{array}$ \\
\hline $\begin{array}{l}\text { Filling screening sheets } \\
\text { by civil registry officers }\end{array}$ & $\begin{array}{l}\text { Completed sheets } \\
\quad(n=3015)\end{array}$ & $\begin{array}{l}\text { Unfilled sheets }(n=50) \\
\text { (absent trained officer) }\end{array}$ \\
\hline $\begin{array}{l}\text { Checking the eligibility } \\
\text { of cases for verbal } \\
\text { autopsies }\end{array}$ & $\begin{array}{l}\text { Deaths eligible for VA survey } \\
\qquad(n=1973)\end{array}$ & $\begin{array}{l}\text { Deaths excluded : no respondent } \\
\text { in Dakar during the collection } \\
\text { period }(n=1042)\end{array}$ \\
\hline $\begin{array}{l}\text { Obtaining consent from the } \\
\text { relative registering the } \\
\text { death }\end{array}$ & $\begin{array}{l}\text { Acceptance by the first } \\
\text { relative }(n=1706)\end{array}$ & $\begin{array}{l}\text { Eligible but relative refusing to } \\
\text { participate } \\
(n=267)\end{array}$ \\
\hline $\begin{array}{l}\text { Obtaining consent from the } \\
\text { relative filling the verbal autopsy } \\
\text { after the mourning period }\end{array}$ & $\begin{array}{l}\text { Acceptance by respondent } \\
\qquad(\mathrm{n}=1334)\end{array}$ & $\begin{array}{l}\text { Respondents refusing to } \\
\text { participate }(n=372)\end{array}$ \\
\hline $\begin{array}{l}\text { Complete verbal autopsy and } \\
\text { questionnaire }\end{array}$ & $\begin{array}{l}\text { Full and usable VAs } \\
\qquad(n=1315)\end{array}$ & $\begin{array}{l}\text { Incomplete and unusable VAs } \\
\qquad(n=19)\end{array}$ \\
\hline
\end{tabular}

\section{A.3. Construction of the accessibility index}

To construct the index of geographical accessibility of civil registration centres, we used the improved two-stage floating attraction area method (E2SFCA) (Luo and Qi, 2009). This method is an enhancement of the two-step floating catchment area (2SFCA) method, which was initially developed to measure spatial accessibility of primary care physicians (Luo and Wang, 2003). The original 2SFCA method measures accessibility as a ratio of primary-care physicians to population in two steps: (1) physicians' availability is measured at their locations as a ratio of physicians to the population in the catchment area, and (2) the ratios are summed around locations for overlapping catchment areas. The E2SFCA method is an improvement in that it does not assume uniform access within the catchment area. Luo and Qi (2009) broke down the catchment areas into three different zones with different travel times and different weights.

We applied the E2SFCA method based on three sets of data, all georeferenced: (1) maps of the Dakar region identifying neighbourhoods, (2) the 2013 census demographic data, and (3) the survey of locations and characteristics of CRVS centres. There are 1,347 neighbourhoods (districts) covering the entire Dakar region for which we had population estimates. As primary administrative units, these neighbourhoods are divided so that none of them straddles two different borough communes, which offers possibilities for aggregating data at this level. However, because the size of the neighbourhoods may mask intraurban disparities in access to civil registration centres, it was decided to use smaller area units (100-by-100-m blocks). The population numbers were broken down into these blocks, multiplying the area of each block by the population density of the district containing it. 
Table 5: Catchment areas according to type of civil registration centre

\begin{tabular}{lllll}
\hline Category & Radius & \multicolumn{2}{l}{ Discrete zone } & $\mathbf{3}$ \\
\cline { 3 - 5 } & & $\mathbf{1}$ & $\mathbf{2}$ & $1-1.5 \mathrm{~km}$ \\
\hline 1 & $1.5 \mathrm{~km}$ & $0-0.5 \mathrm{~km}$ & $0.5-1 \mathrm{~km}$ & $2-3 \mathrm{~km}$ \\
3 & $3 \mathrm{~km}$ & $0-1 \mathrm{~km}$ & $1-2 \mathrm{~km}$ & $4-6 \mathrm{~km}$ \\
\hline
\end{tabular}

The CRVS diagnostic survey provided information on the number of officers in each of the 72 civil registration centres, the GPS coordinates of these centres, the proximity of a significant infrastructure or equipment, and a theoretical catchment area. The analysis of the catchment areas (based on reports from the staff in registration offices) led us to define three categories of civil registration centres (Table 5).

Two sets of weights were also computed for each CRVS centre, one based on the staff in each centre and one based on the proximity of a civil registration centre with a significant infrastructure or equipment (hospital, health centre, petrol station, school, etc.). Since we did not have information on the transportation network, we used Euclidean distance as a measure of travel time.

The calculation of accessibility was done in two steps. First, we proceeded from the geographical position of each civil status centre to search for all the centroids of the 0.01 $\mathrm{km}^{2}$ blocks included in the defined catchment area and calculated the ratio of civil status centres to the population. The initial ratios in overlapping areas (where populations potentially have access to several centres) were then added together. For more details on the method, we refer the reader to Ndonky et al. (2015) and Luo and Qi (2009).

Three types of indicators were initially computed: the unweighted centres-to-population ratio, the same ratio weighted by the size of the staff in each centre only, and finally, this ratio weighted by the size of the staff and the proximity to other infrastructure and equipment. There was a very strong statistical correlation between these three indicators $(>0.94)$. We retained the ratio based on weights related to staff and proximity to other infrastructure for our analysis.

The indicator of geographical accessibility to civil registration centres in the Dakar region is presented below for 100-by-100-m blocks. The estimates used in the main manuscript were obtained after aggregating at the level of borough communes. Overall, the map below shows large spatial disparities in geographical accessibility of civil registration centres, with a sharp contrast between the western parts of the region with high accessibility and the east with low accessibility. However, in both the western and eastern parts, there are pockets of high accessibility, particularly around the cities of Rufisque and Diamniadio. The northeast is the area most deprived in terms of civil registration centres, while the west is characterized by strong spatial disparities. The southwest (Dakar Plateau, Medina, Hann Bel Air, Fann), the Niayes region (Golf Sud and Pikine Ouest), and Mbao have the highest accessibility. On the other hand, in the northwest (Ngor, Yoff, Parcelles Assainies), there are areas of poor accessibility. 


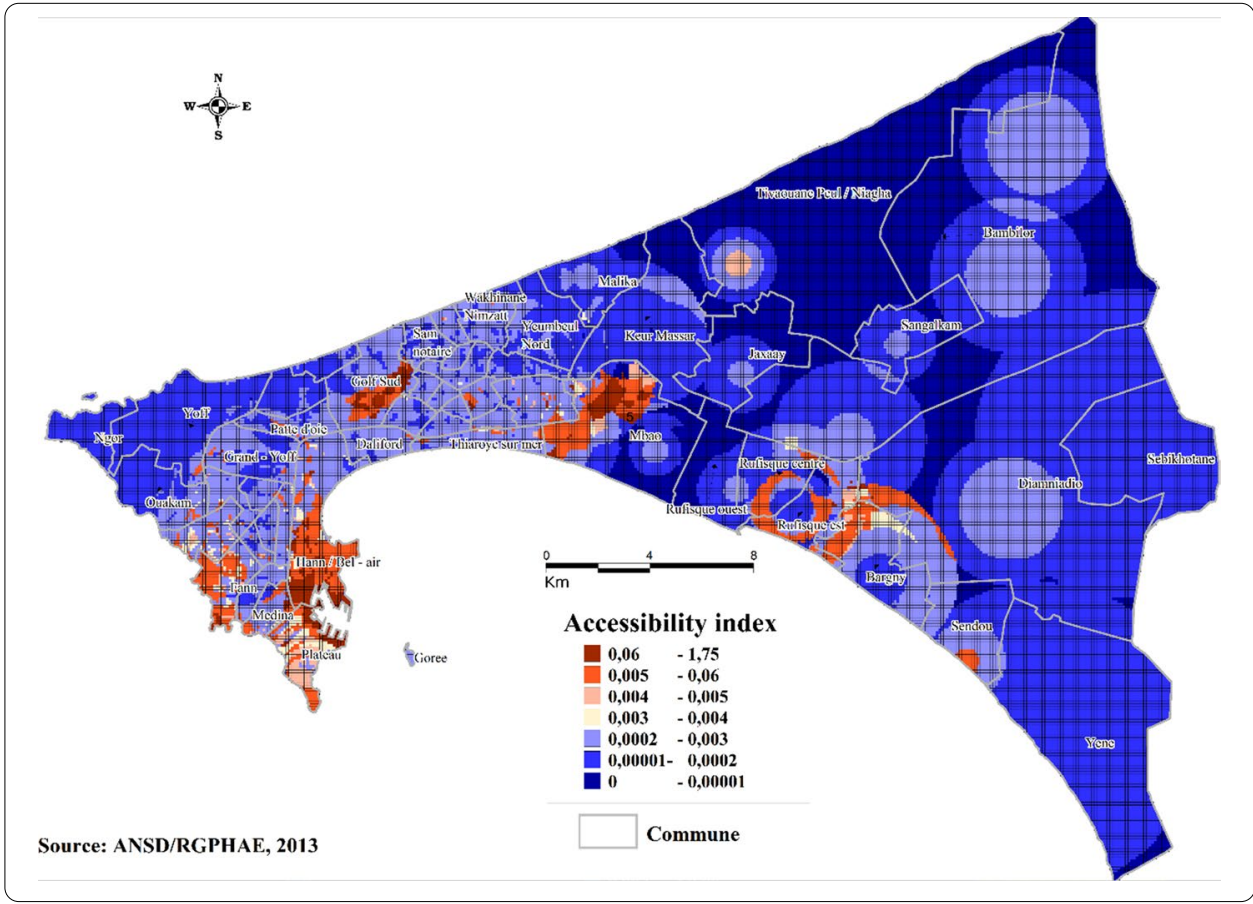

\section{Acknowledgements}

We thank Irina Dincu from IDRC, Romesh Silva from UNFPA and two anonymous reviewers for their comments on an earlier version of this article.

\section{Authors' contributions}

$\mathrm{AF}$ and BM drafted the first version of the manuscript and performed the statistical analysis. KN supervised the collection of data on reasons for registering deaths and sources of information as part of the verbal autopsy study. SM provided data on accessibility to vital registration centers and reviewed the manuscript. AN analyzed the data on accessibility to vital registration centers and developed the corresponding index. All authors read and approved the final manuscript.

\section{Funding}

This research was funded by ARES-CCD (https://www.ares-ac.be) as part of the ASSESS PRD project (http://assess-sn. org/).

\section{Availability of data and materials}

This study is based on an excerpt from the 2013 census data and the 2018 verbal autopsy study, which are available from the Agence Nationale de la Statistique et de la Démographie (ANSD) upon reasonable request.

\section{Declarations}

\section{Competing interests}

The authors declare that they have no competing interests.

\section{Author details}

${ }^{1}$ Agence Nationale de la Statistique et de la Démographie (ANSD), Dakar, Senegal. ${ }^{2}$ Centre de recherche en démographie, UCLouvain, Ottignies, Belgium. ${ }^{3}$ Université Gaston Berger (UGB), Saint-Louis, Senegal. ${ }^{4}$ Université de Thiès, Thiès, Senegal.

Received: 5 May 2021 Accepted: 17 August 2021

Published online: 08 September 2021

\section{References}

Adair, T., \& Lopez, A. D. (2018). Estimating the completeness of death registration: An empirical method. PLOS ONE, 13(5), e0197047.

Bennouna, C., Feldman, B., Usman, R., Adiputra, R., Kusumaningrum, S., et al. (2016). Using the three delays model to examine civil registration barriers in Indonesia. PLOS ONE, 11(12), e0168405. 
Bhatia, A., Ferreira, L. Z., Barros, A. J. D., \& Victora, C. G. (2017). Who and where are the uncounted children? Inequalities in birth certificate coverage among children under five years in 94 countries using nationally representative household surveys. International Journal for Equity in Health, 16, 148.

Byass, P., Hussain-Alkhateeb, L., D'Ambruoso, L., Clark, S., Davies, J., et al. (2019). An integrated approach to processing WHO-2016 verbal autopsy data: The InterVA-5 model. BMC Medicine, 17, 102.

Castle, S., Ortiz, E. \& Setel, P. (2020). Demand-side factors related to the registration of births, marriages, and deaths: A literature review. CRVS working paper series, Issue 2. https://crvssystems.ca/sites/default/files/assets/images/Issue2_ Demand\%20side\%20factors_e.pdf. Accessed 15 April 2021.

Center for Excellence for CRVS Systems. (2019)/ Empowering women and girls through civil registration systems. Knowledge Briefs on Gender and CRVS, Brief 2, Paper 4. Centre of Excellence for CVRS Systems. https://crvssystems.ca/sites/ default/files/inline-files/CRVS_Gender_2.4_Empower_e.pdf. Accessed 15 April 2021.

de Savigny, D., Riley, I., Chandramohan, D., Odhiambo, F., Nichols, E., et al. (2017). Integrating community-based verbal autopsy into civil registration and vital statistics (CRVS): System-level considerations. Global Health Action, 10(1), 1272882.

Delaunay, V., Douillot, L., Diallo, A., Dione, D., Trape, J.-F., et al. (2013). Profile: The Niakhar Health and Demographic Surveillance System. International Journal of Epidemiology, 42(4), 1002-1011.

Dlodlo, R. A., Fujiwara, P. I., Hwalima, Z. E., Mungofa, S., \& Harries, A. D. (2011). Adult mortality in the cities of Bulawayo and Harare, Zimbabwe: 1979-2008. Journal of the International AIDS Society, 14(Suppl 1), S2.

Duff, P., Kusumaningrum, S., \& Stark, L. (2016). Barriers to birth registration in Indonesia. Lancet Global Health, 4(4), e234-235.

Fagernäs, S., \& Odame, J. (2013). Birth registration and access to health care: An assessment of Ghana's campaign success. Bulletin of the World Health Organization, 91(6), 459-464.

Fargues, P. \& Nassour, O. (1988). Douze ans de mortalité urbaine au Sahel: Niveaux, tendances, saisons et causes de mortalite à Bamako 1974-1985 [Twelve years of urban mortality in the Sahel: Levels of mortality, trends, seasonality and causes of death in Bamako 1974-1985]. Travaux et documents, Cahier de l'INED 123.

Fisker, A., Rodrigues, A., \& Helleringer, S. (2019). Differences in barriers to birth and death registration in Guinea-Bissau: Implications for monitoring national and global health objectives. Tropical Medicine and International Health, 24(2), $166-174$.

Garenne, M., Madison, M., Tarantola, D., Zanou, B., Aka, J., et al. (1995). Conséquences démographiques du sida en Abidjan: 1986-1992 [Demographic consequences of AIDS in Abidjan: 1986-1992] (p. 10). Les études du CEPED.

Haider, M.M., Alam, N., Ibn Bashar, M., Helleringer, S. (2021). Adult death registration in Matlab, rural Bangladesh: completeness, correlates, and obstacles. Genus, 77, 13.

Kabadi, G., Mwanyika, H. \& de Savigny, D. (2013). Mobile phone SMS support to improve coverage of birth and death registration: A scalable solution. Health Information Systems Knowledge Hub, School of Population Health, The University of Queensland. https://core.ac.uk/download/pdf/18410813.pdf, Accessed 15 April 2021.

Luo, W., \& Qi, Y. (2009). An enhanced two-step floating catchment area (E2SFCA) method for measuring spatial accessibility to primary care physicians. Health \& Place, 15(4), 1100-1107.

Luo, W., \& Wang, F. (2003). Spatial accessibility to primary care and physician shortage area designation: A case study in Illinois with GIS approaches. In R. Skinner \& O. Khan (Eds.), Geographic information systems and health applications (pp. 260-278). Idea Group Publishing.

Masquelier, B., Pison, G., Rakotonirina, J., \& Rasoanomenjanahary, A. (2019). Estimating cause-specific mortality in Madagascar: An evaluation of death notification data from the capital city. Population Health Metrics, $17,8$.

Mikkelsen, L., Phillips, D. E., AbouZahr, C., Setel, P. W., de Savigny, D., Lozano, R., \& Lopez, A. D. (2015). A global assessment of civil registration and vital statistics systems: Monitoring data quality and progress. Lancet, 386(10001), 1395-1406.

Moultrie, T., Dorrington, R., Hill, A., Hill, K., Timæus, I., \& Zaba, B. (2013). Tools for demographic estimation. International Union for the Scientific Study of Population.

Agence Nationale de la Statistique et de la Démographie. (2014). Rapport définitif du RGPHAE 2013 [Final report of the 2013 census]. Agence nationale de la statistique et de la démographie, Sénégal.

Ndonky, A., Oliveau, D., Lalou, R., \& Dos Santos, S. (2015). Mesure de l'accessibilité géographique aux structures de santé dans l'agglomération de Dakar. Cybergeo, December 2015. https://doi.org/10.4000/cybergeo.27312.

Niamba, L. (2020). Geographical and gender disparities in the registration of births, marriages, and deaths in the Nouna Health and Demographic Surveillance System, Burkina Faso. CRVS working paper series, Issue 1. https://crvssystems.ca/sites/ default/files/assets/files/WorkingPaperSeries_Issue1_Niamba_e_WEB.pdf, Accessed 15 April 2021.

Groupe d'Étude de Recherche et d'Appui au Développement. (2014). Étude diagnostique des centres d'état civil au Sénégal-rapport de synthèse [Diagnostic study of civil registration centres in Senegal—summary report]. PAMEC, December 2014.

Phillips, D. E., AbouZahr, C., Lopez, A. D., Mikkelsen, L., de Savigny, D., Lozano, R., Wilmoth, J., \& Setel, P. W. (2015). Are well functioning civil registration and vital statistics systems associated with better health outcomes? Lancet, 386(10001), 1386-1394.

Pison, G., Beck, B., Ndiaye, O., Diouf, P. N., Senghor, P., et al. (2018). HDSS Profile: Mlomp Health and Demographic Surveillance System (Mlomp HDSS) Senegal. International Journal of Epidemiology, 47(4), 1025-1033.

Pison, G., Douillot, L., Kante, M., Ndiaye, P., Diouf, P., et al. (2014). Health \& Demographic Surveillance System Profile: Bandafassi Health and Demographic Surveillance System (Bandafassi HDSS), Senegal. International Journal of Epidemiology, 43(3), 739-748.

Rao, C., Bradshaw, D., \& Mathers, C. (2004). Improving death registration and statistics in developing countries: Lessons from sub-Saharan Africa. Southern African Journal of Demography, 9(2), 81-99.

Salem, G. (1993). Géographie de la mortalité et de la natalité à Pikine (Sénégal): Intérêts et limites des données d'état civil dans les villes africaines [Geography of mortality and natality in Pikine (Senegal): Advantages and limitations of civil status data in African cities]. Social Science and Medicine, 36(1), 1297-1311. 
Suthar, A. B., Khalifa, A., Yin, S., Wenz, K., Ma Fat, D., et al. (2019). Evaluation of approaches to strengthen civil registration and vital statistics systems: A systematic review and synthesis of policies in 25 countries. PLoS Medicine, 16(9), e1002929.

Szwarcwald, C. L., de Frias, P. G., Júnior, P. R., \& da Silva de Almeida, W., Neto OL. . (2014). Correction of vital statistics based on a proactive search of deaths and live births: Evidence from a study of the North and Northeast regions of Brazil. Population Health Metrics, 12, 16.

Thaddeus, S., \& Maine, D. (1994). Too far to walk: Maternal mortality in context. Social Science \& Medicine, 38(8), 1091-1110.

UNICEF, (2005). The "rights" to start a life, a statistical analysis of birth registration, UNICEF. https://unstats.un.org/unsd/vital statkb/KnowledgebaseArticle51062.aspx, Accessed 15 April 2021.

United Nations. (2017). Principles and recommendations for population and housing censuses, revision 3. Dept. of International Economic and Social Affairs, United Nations.

United Nations Children's Fund. (2013). Every child's birth right: Inequities and trends in birth registration. New York: UNICEF. Available at https://data.unicef.org/resources/every-childs-birth-right-inequities-and-trends-in-birth-registration/, Accessed 15 April 2021.

World Bank and World Health Organization. (2014), Global civil registration and vital statistics: Scaling up investment plan 2015-2024. Available at http://www.worldbank.org/content/dam/Worldbank/document/HDN/Health/CRVS\%20Sca ling-up\%20plan\%20final\%205-28-14web.pdf, accessed 15 April 2021.

World Health Organization. (2018). World health statistics 2018: Monitoring health for the SDGs, sustainable development goals. https://apps.who.int/iris/handle/10665/272596, Accessed 15 Apr 2021.

\section{Publisher's Note}

Springer Nature remains neutral with regard to jurisdictional claims in published maps and institutional affiliations.

\section{Submit your manuscript to a SpringerOpen ${ }^{\circ}$ journal and benefit from:}

- Convenient online submission

- Rigorous peer review

- Open access: articles freely available online

- High visibility within the field

- Retaining the copyright to your article

Submit your next manuscript at $\boldsymbol{\Delta}$ springeropen.com 